\begin{tabular}{ll}
\hline \hline MINING AND METALLURGY INSTITUTE BOR & ISSN: 2334-8836 (Štampano izdanje) \\
UDK: 622 & ISSN: 2406-1395 (Online) \\
\hline \hline
\end{tabular}

UDK: $669.35,5 / .71(045)=111$

doi:10.5937/mmeb1802079K

Ana Kostov", Aleksandra Milosavljević, Zdenka Stanojevic Šimšić, Corneliu Craciunescu**

\title{
CHARACTERIZATION OF COPPER-BASED SHAPE MEMORY ALLOY WITH ZINC AND ALUMINUM ${ }^{* * * *}$
}

\begin{abstract}
Copper-based shape memory alloy with zinc and aluminum was manufactured, plastically deformed, heat treated and characterized in terms of the physico-mechanical, structural and micro-structural investigation. Typical martensitic microstructure with twins is revealed by the optical and electron microscopy. The presence of martensite in the structure was further confirmed through an X-ray diffraction. Toughness and hardness of the alloy are investigated, too. Optimal properties are obtained for the condition of the alloy that was subjected to the heat treatment according to the following scheme: annealing at $850^{\circ} \mathrm{C}$ and $900^{\circ} \mathrm{C}(10 \mathrm{~min})+$ quenched in water + aging at $400^{\circ} \mathrm{C}(1$ hour $)+$ air cooling.

Keywords: shape memory, SEM-EDS, hardness, copper-zinc-aluminum alloy, martensitic structure
\end{abstract}

\section{INTRODUCTION}

The effect of shape memory is ability of some metals and alloys deformed in the martensite state or at temperature interval of martensitic transformation to regain their original shape during the heating process due to a complete or almost complete absence of deformation $[1,2]$.

The heating process causes restoration of crystals in the high-temperature phase called beta or parent phase, and removal of plastic deformation. In the same time, the all physical and mechanical properties are restored.

During the shape recovering process, the alloys can produce a displacement or force, or combination of the two, as a function of temperature. The starting force of recovering shape process is difference between the free energies of parent and martensitic phases during the reverse transformation. The com-

plete shape recovering is only notice if the martensitic transformation is crystallography reverses, and if the deformation process is done without the plane shearing $[2,3]$.

The shape memory effect has been studied for many binary and ternary alloys, as well as for some pure metals. However, a wide application can be found only for the nitinol (Ni-Ti alloys) and copper-based alloys that show shape memory effect. Copper-based alloys, compared to nitinol alloys, possess somewhat lower mechanical properties due to their larger grain size and elastic anisotropy [4]. But, they can be improved, considerably without deterioration of the shape memory effect, by the small grain, method of rapid solidification, sinter metallurgy, or by adding the elements such as $\mathrm{Zr}, \mathrm{V}, \mathrm{B}, \mathrm{Ti}, \mathrm{Cr}$, etc. [5].

\footnotetext{
* Mining and Metallurgy Institute Bor, Zeleni bulevar 35, 19210 Bor, Serbia

** Politehnica University of Timisoara, Bd. Mihai Viteazul 1, RO-300006 Timisoara, Romania

${ }^{* * *}$ The authors acknowledge the support by a grant of the Romania-Republic of Serbia IPA Crossborder Cooperation Programme through the Project MIS ETC No. 1328 "Pole of Collaboration in the New Functional Alloys"
} 


\section{COPPER-BASED SHAPE MEMORY ALLOYS}

Copper-based alloy with shape memory effect are very commercial and they are mainly alloys with zinc, aluminum and nickel. Figure 1 shows the liquidus projec

tion in the copper-based alloys with zinc and aluminum, while Table 1 gives a review of the possible invariant reaction in the same system of alloy [6].

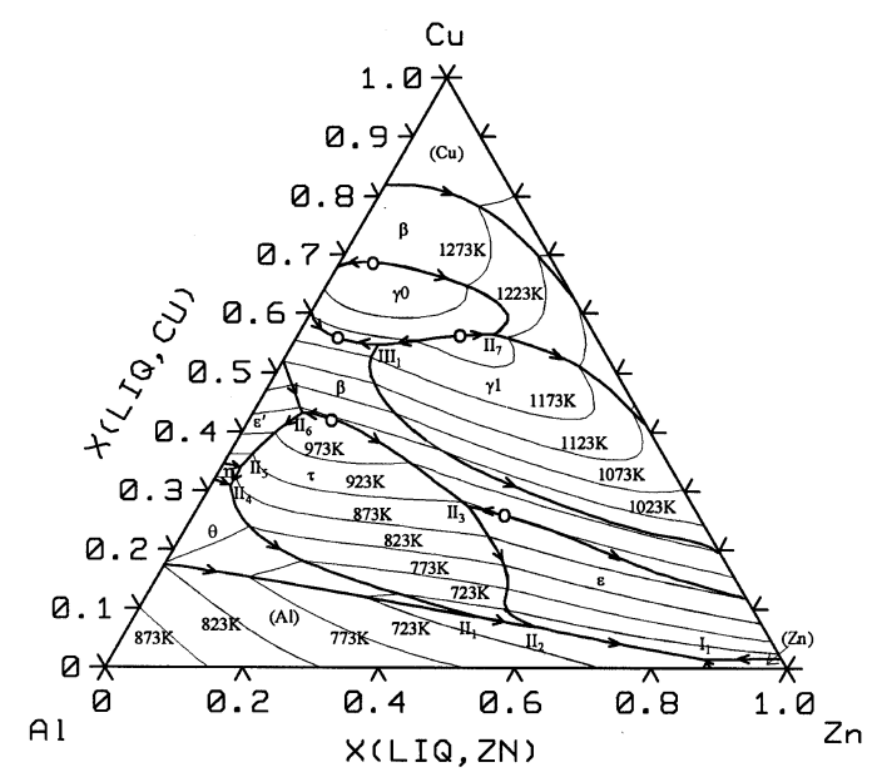

Figure 1 Calculated liquidus projection in the Cu-Zn-Al system of alloy

Table 1 Calculated invariant reactions in the $\mathrm{Cu}-\mathrm{Zn}$-Al system of alloy

\begin{tabular}{|c|c|c|}
\hline Reaction & Temperature, K & Composition of liquid phase \\
\hline $\mathrm{L}+\theta \rightarrow(\mathrm{Al})+\tau$ & 698 & $\mathrm{Cu} 8,6 \mathrm{Zn} 50,5 \mathrm{Al} 40,9$ \\
\hline $\mathrm{L}+\tau \rightarrow(\mathrm{Al})+\varepsilon$ & 694 & $\mathrm{Cu} 6,8 \mathrm{Zn} 60,1 \mathrm{Al} 33,1$ \\
\hline $\mathrm{L} \rightarrow(\mathrm{Al})+(\mathrm{Zn})+\varepsilon$ & 654 & $\mathrm{Cu} 1,6 \mathrm{Zn} 87,2 \mathrm{Al11}, 2$ \\
\hline $\mathrm{L}+\beta \rightarrow \varepsilon+\tau$ & 917 & $\mathrm{Cu} 27,4 \mathrm{Zn} 39,5 \mathrm{Al} 33,1$ \\
\hline $\mathrm{L}+\eta \rightarrow \tau+\theta$ & 853 & $\mathrm{Cu} 31,2 \mathrm{Zn} 2 \mathrm{Al} 66,8$ \\
\hline $\mathrm{L}+\varepsilon^{\prime} \rightarrow \tau+\eta$ & 893 & $\mathrm{Cu} 34,3 \mathrm{Zn} 2 \mathrm{Al} 62,8$ \\
\hline $\mathrm{L}+\beta \rightarrow \tau+\varepsilon^{\prime}$ & 1010 & $\mathrm{Cu} 43,5 \mathrm{Zn} 6,9 \mathrm{Al} 49,6$ \\
\hline $\mathrm{L}+\gamma^{\circ} \rightarrow \beta+\gamma$ & 1226 & $\mathrm{Cu} 56,4 \mathrm{Zn} 28,6 \mathrm{Al} 15$ \\
\hline $\mathrm{L}+\gamma^{\circ}+\gamma^{\circ} \rightarrow \beta$ & 1197 & $\mathrm{Cu} 54,6 \mathrm{Zn} 12,6 \mathrm{Al} 32,8$ \\
\hline
\end{tabular}

The possibility of shape memory effect depends upon the alloy ability to undergo the thermo-elastic martensite deformation.
The alloy is first cooled and transferred to the martensitic phase, when there is q possibility of mechanical deformation. As 
long as the lower temperature, the alloy is deformed, or if heated, martensite again deformed into the austenite and the alloy returns to its ori-ginal shape.

Martensitic transformation does not occur at a certain temperature, yet there is a whole temperature range which is different for each monitored system.

Various deformation temperatures and the corresponding voltage curves for the copper-based alloy with zinc and aluminum are shown in Fi-gure 2.

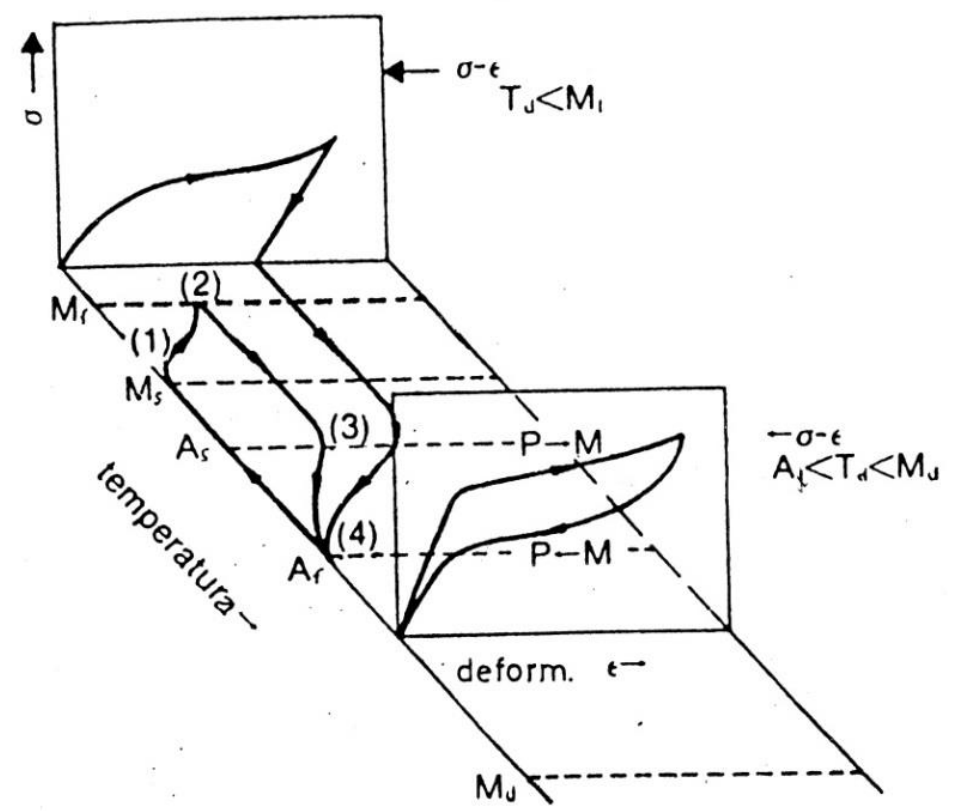

Figure 2 Schematic overview of the voltage curves depending on deformation temperature (Ms-temperature of beginning martensite formation at cooling; Mf-temperature of the martensitic transformation ending; As-starting temperature of high temperature phase formation; Af-ending temperature of high temperature phase formation at heating; Md-below this temperature martensite can be reversed into the original phase)

In the upper left corner in Figure 2, the alloy deformation below the Mf temperature is shown, while alloy is fully in martensitic condition. For a relatively low stress, there is a possibility when the deformation can be deposited in the martensite structure at certain stress. When unloading once, the elastic distance can be observed in any metal. Heating to Af temperature, martensite with added deformation disappears and the original structure returns.
In contrast, in the lower right corner in Figure 2, the curve corresponding to the alloy deformed between the temperatures the Af and Md is shown, while the alloy is in the initial phase at high temperature. Here is a tensile martensite before the applied deformation $(\mathrm{P} \rightarrow \mathrm{M})$. After release, the martensitic structure is unstable, and is converted to the original phase $(\mathrm{P} \leftarrow \mathrm{M})$. During this reversible process, each deformation, incorporated into the tensile - martensite, disa- 
ppears and the material returns to its original shape. This behavior of materials was called the pseudo-elasticity.

The copper-based shape memory alloys with zinc and aluminum are widely used in the industry as the thermostats, control equipment, connectors, etc. The most obvious examples are the various types of springs with different systems for remote regulation and control. The shape memory alloys based on copper also have wide applications in home use as the constitutive elements of various assemblies. Their great advantage over the other types of smart materials alloys is a low price, as well as the role of environmental friendly materials.

\section{EXPERIMENTAL}

The copper-based shape memory alloy with zinc and aluminum are usually obtained by the classical method of melting, casting and manufacturing. Generally, all alloys with martensite structure have the heavy plastically deformation consisting of few cycles of rolling at hot and drawing at cold with the series of intermediate annealing treatments, from ingots to rods and wires of small cross-section. However, it is necessary to keep the chosen composition of alloy during the production process, which is difficult by the zinc evaporation during the casting process. Also, the plastically deformation of these alloys is heavy, with many operations of rolling, drawing and intermediate annealing treatments.

Because of that, the copper-based shape memory alloy with zinc and aluminum is obtained using the technology of continuous casting of wire and profiles of small diameters, developed in the Mining and Metallurgy Institute Bor for some pure metals [7].

The principle of this method of continuous casting has used the procedure of crystallization above the melt for directly obtaining the copper-based shape memory $8 \mathrm{~mm}$ wire. The principle of technology is as follows [7]: The cooler for copper-based shape memory wire casting is dipped into the melt to a depth of $h$. The protection shell made of heat-resistant material, which does not react with molten alloy and layer of heatinsulation material, protects the cooler from the influence of melt and high temperatures. Hydrostatic pressure of surrounding melt drives the molten alloy into a graphite crucible. The molten alloy hardens in the crucible by the heating exchange through the primary part of crystallizer, which is water-cooled. Hardened wire leaves the graphite crucible at a high temperature. Vacuum is used for prevention the cast wire oxidation, caused by the high temperature on its surface. Apart from the above mentioned role, the vacuum serves also for provision the required differential pressure inside cooler enabling a penetration of molten alloy into the graphite crucible. For prevention the cast wire oxidation after leaving the cooler, the temperature on its surface should be below $60^{\circ} \mathrm{C}$. Cooling provides this cast wire in the secondary part of crystallizer. Cast wire drawing is done according to the drag-pause schematic. The process stability is ensured by adjustment the wire drawing speed and heat removal from its side surface.

\section{RESULTS AND DISCUSSION}

The chemical composition of obtaining 8 $\mathrm{mm}$ wire is: $\mathrm{Cu}-69.7 \%, \mathrm{Zn}-26.3 \%$ and $\mathrm{Al}-$ $4 \%$. The samples of wires are treated in the aim to obtain the wire of $1.8 \mathrm{~mm}$ with the shape memory effect as follows: 2 h of homogenization at $800^{\circ} \mathrm{C}$ in low oxidation atmosphere, then drawing to the dimension $4 \times 4$, with the thermal treatment: $15 \mathrm{~min}$ of annealing at $400^{\circ} \mathrm{C}$, quenching in water, 120 min annealing at $550^{\circ} \mathrm{C}$, cooling in furnace to $450^{\circ} \mathrm{C}$ and air cooling and drawing to the dimension $1.8 \mathrm{~mm}$. In the aim to reach the martensite structure, samples are heating $5 \mathrm{~min}$ in nitrogen atmosphere at $800^{\circ} \mathrm{C}$ andquenched in cold water and in martensite state the alloy was memorized. 
In the aim to determine the characteristics of obtained shape memory alloy, the investigations of mechanical properties, structural and micro-structural analysis, as well as SEM-EDS and X-ray are done. The obtained results are shown in Table 1 and Figures 3-8, respectively.

Table 2 Results of physic-mechanical properties toughness and hardness by Vicker's method

\begin{tabular}{|c|l|c|c|}
\hline \multirow{2}{*}{$\mathbf{N}^{\mathbf{0}}$} & \multicolumn{1}{|c|}{ Condition of materials } & Toughness & Hardness \\
\cline { 3 - 4 } & & $\mathbf{J} / \mathbf{c m}^{\mathbf{2}}$ & HV \\
\hline 0 & As-cast condition & 20 & 314 \\
\hline 1 & Hot-rolled at $850^{\circ} \mathrm{C}$ & 40 & 354 \\
\hline 2 & Annealing at $850^{0} \mathrm{C}(10 \mathrm{~min})$, quenched in water & 34 & 379 \\
\hline 3 & Annealing at $900^{\circ} \mathrm{C}(10 \mathrm{~min})$, quenched in water & 33 & 368 \\
\hline 4 & $(2)+$. ageing at $400^{\circ} \mathrm{C}(1 \mathrm{~h})+$ air cooling & 22 & 492 \\
\hline 5 & $(2)+$. ageing at $450^{0} \mathrm{C}(1 \mathrm{~h})+$ air cooling & 16 & 475 \\
\hline 6 & $(2)+$. ageing at $500^{\circ} \mathrm{C}(1 \mathrm{~h})+$ air cooling & 26 & 448 \\
\hline 7 & $(2)+$. ageing at $450^{\circ} \mathrm{C}(1 \mathrm{~h})+$ cooling in furnace & 21 & 454 \\
\hline 8 & $(3)+$. ageing at $400^{\circ} \mathrm{C}(1 \mathrm{~h})+$ air cooling & 20 & 504 \\
\hline 9 & $(3)+$. ageing at $450^{\circ} \mathrm{C}(1 \mathrm{~h})+$ air cooling & 19 & 478 \\
\hline 10 & $(3)+$. ageing at $500^{\circ} \mathrm{C}(1 \mathrm{~h})+$ air cooling & 18 & 464 \\
\hline 11 & $(3)+$. ageing at $450^{\circ} \mathrm{C}(1 \mathrm{~h})+$ cooling in furnace & 23 & 479 \\
\hline
\end{tabular}

According to the results of mechanical investigation, shown in Table 2, it is noticed that the optimal characteristics of alloy are obtained for the following state

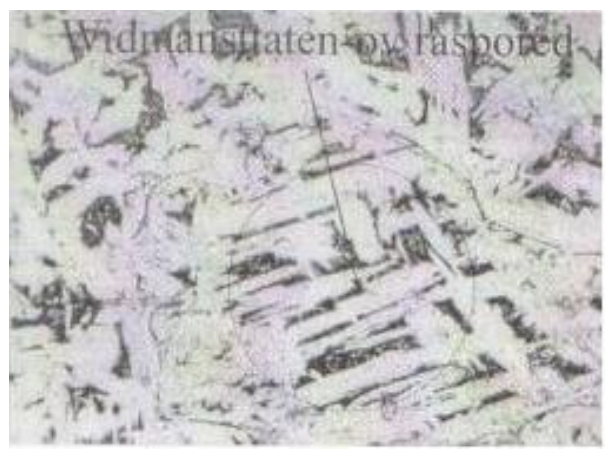

Figure 3 Microstructure of the as-cast alloy, (x960) of materials: annealing, quenched in water, ageing at $400^{\circ} \mathrm{C} 1$ hour, and then air cooling. This conclusion is verified by the metallography, Figures 3-8.

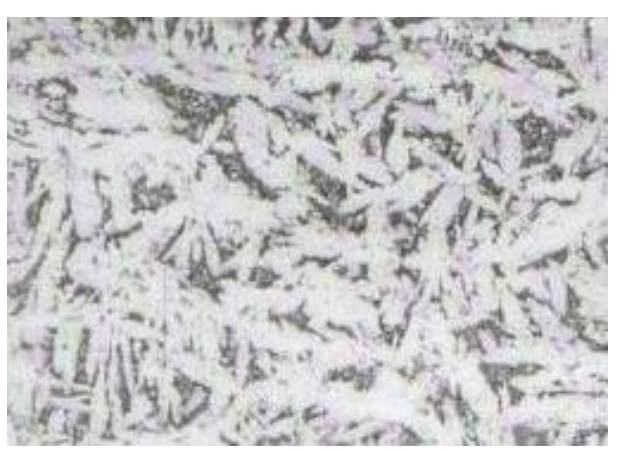

Figure 4 Microstructure of the alloy, hot deformed (x960) 


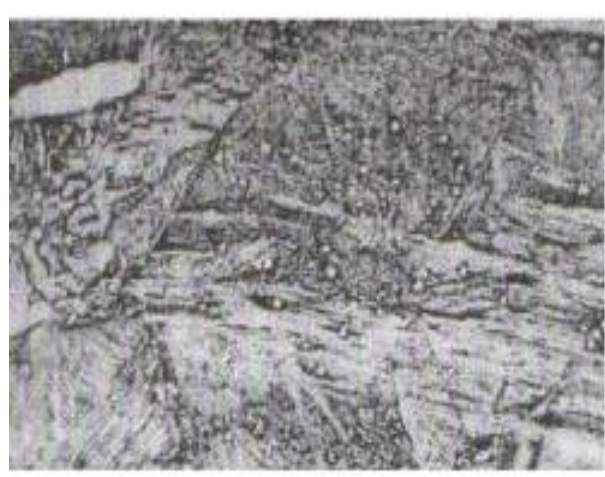

Figure 5 Microstructure of the alloy, annealed at $850^{\circ} \mathrm{C}$ for 10 min and water quenched (x960)

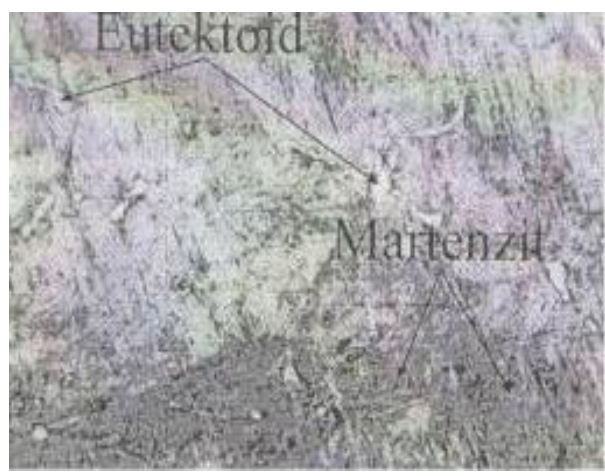

Figure 7 Microstructure of the alloy quenched from $850^{\circ} \mathrm{C}$ and aged at $400^{\circ} \mathrm{C}$ for $1 \mathrm{~h}(x 960)$

Microstructure of the cast alloy consists of a lot of big bright crystal $\alpha$-solid solution in the dark basically $\beta$-crystals (Fig. 3). In appearance, this structure corresponds to the martensite structure with notable locality Widmanstatten structure. This structure is not favourable for the cold plastic deformation, because the present structure is very brittle, and therefore the only possible deformation is at elevated temperatures.

Hot-processed alloy sample consists of bright crystals of $\alpha$-solid solution surround-

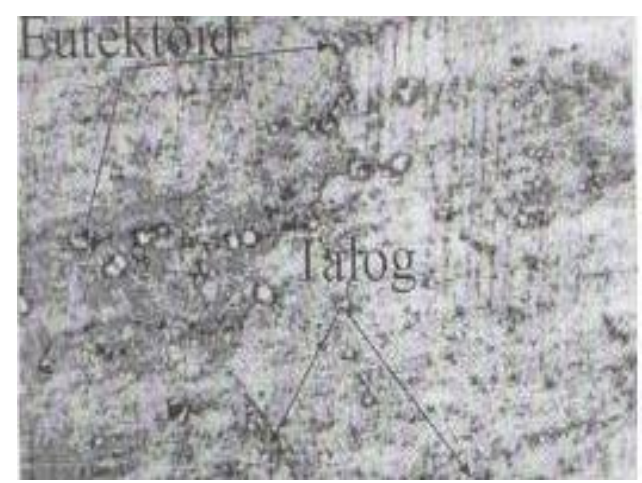

Figure 6 Microstructure of the alloy, annealed at $900^{\circ} \mathrm{C}$ for $10 \mathrm{~min}$ and water quenched (x960)

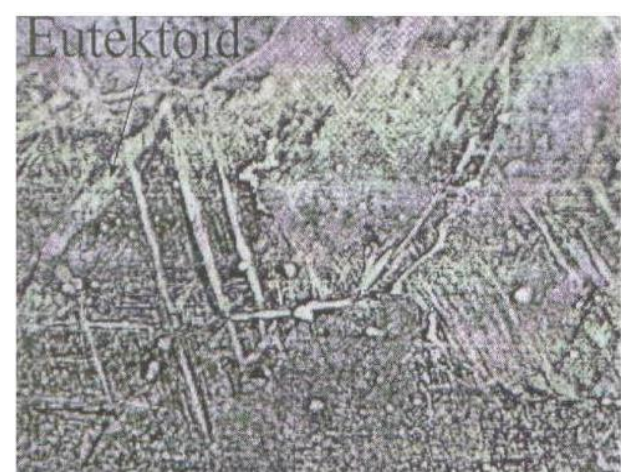

Figure 8. Microstructure of alloy quenched from $900^{\circ} \mathrm{C}$ and aged at $400^{\circ} \mathrm{C}$ for $1 \mathrm{~h}(x 960)$

ding the crystals of dark $\beta$-phase. Between the crystals of $\alpha$-solid solution in the dark based $\beta$-phase particles extracted notice precipitate, but in a very small volume shares (Figure 4). Compared to the as-cast structure, the microstructure is somewhat finer, because the $\alpha$-solid solution is better deployed in the $\beta$-base as a result of deformations in hot condition.

The microstructure of annealed state of the alloy is given in Figures 5 and 6 . It is noted that the large polygonal grains are 
formed with the present of eutectoid and precipitate deposited on the grain boundaries. Due to higher temperatures (Figure 6), there is a complete transformation of martensite structure.

Microstructure of the aging state of alloy consists of the large polygonal grains with separate participate and eutectoid on the grain boundaries. In the alloy sample, quenched in water from $850^{\circ} \mathrm{C}$, the appearance of residual martensite structure is observed with a fine needle (Figure 7), while the sample quenched from $900^{\circ} \mathrm{C}$ and subsequently ageing at $400^{\circ} \mathrm{C}$, the presence of residual martensite and eutec toid is noted, but there has been a phenomenon of thermal deposition in the grain boundaries and with in each grain (Figure 8). In this sample, the martensite structure with the Widmanstatten schedule is observed, since the $\alpha$-solid solution is separated in the form of martensitic needles.

The typical martensite twins are also observed on a scanning electron microscope image (Figures 9 and 10), while the elemental analysis (EDS), detailed in Figure 11 locates the manufactured alloy in the compositional range for the shape memory alloys in the $\mathrm{Cu}-\mathrm{Zn}-\mathrm{Al}$ system.

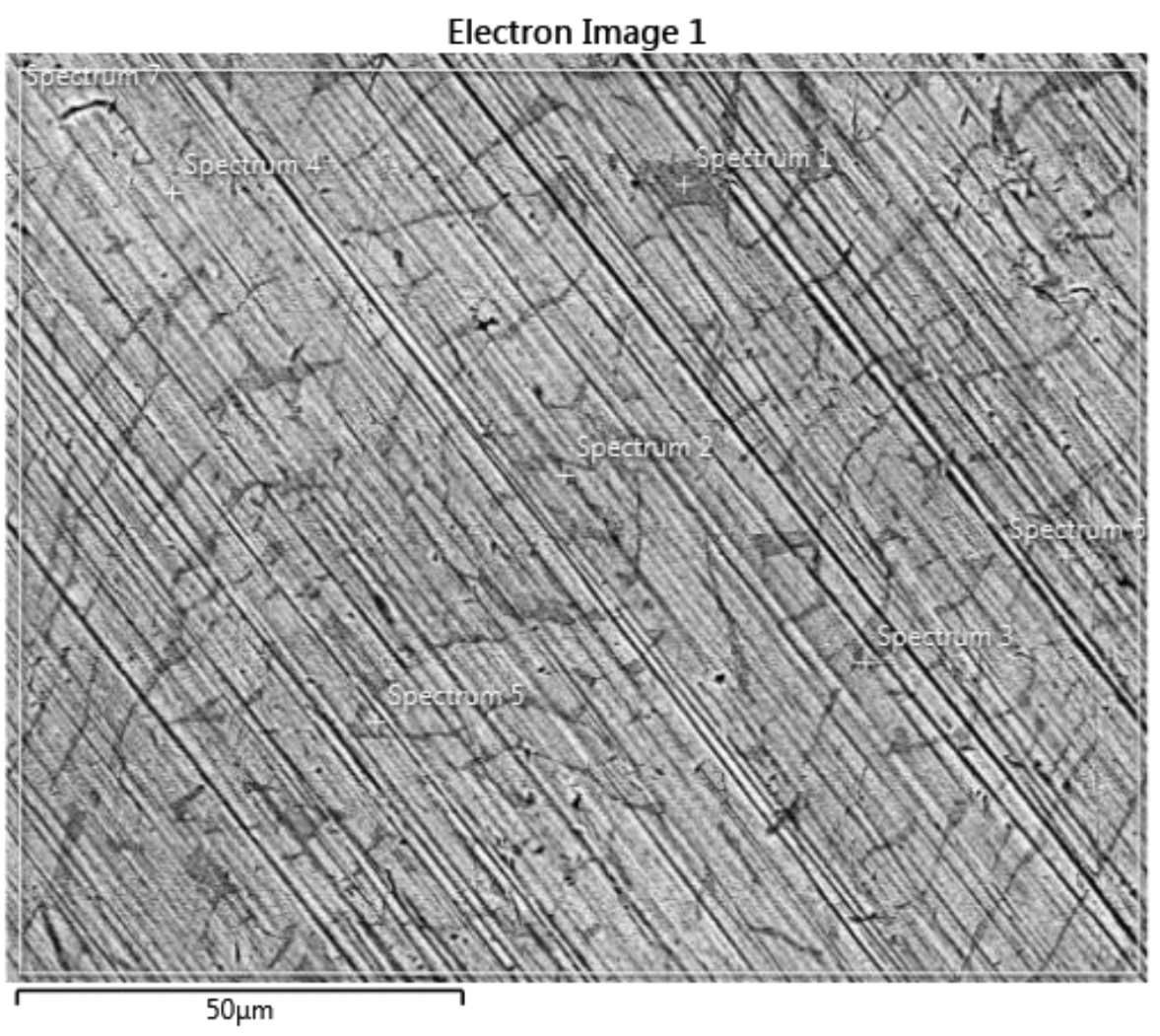

Figure 9 SEM of the alloy quenched from $900^{\circ} \mathrm{C}$ and aged at $400^{\circ} \mathrm{C}$ for $1 \mathrm{~h}$ 

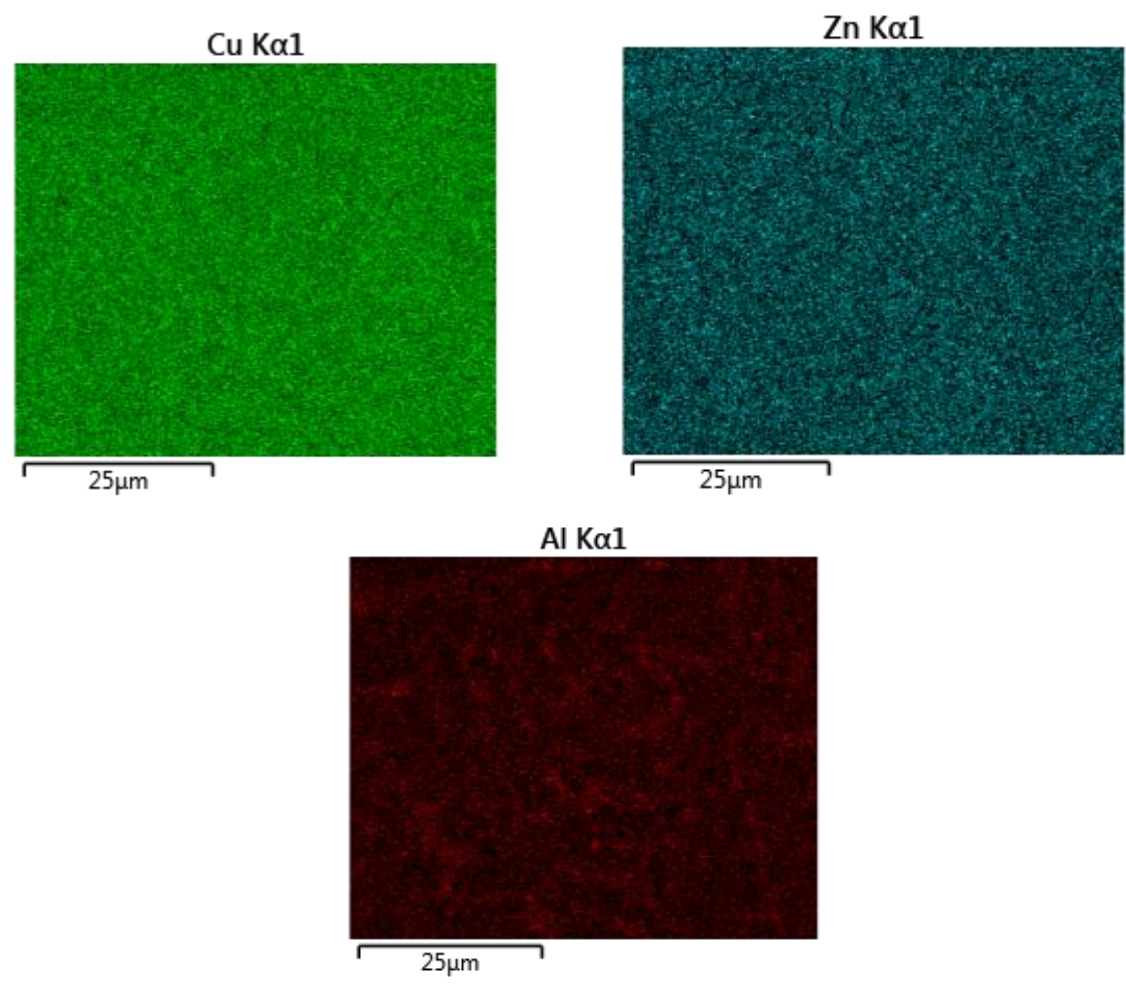

Figure 10 SEM map of based elements of the alloy quenched from $900^{\circ} \mathrm{C}$ and aged at $400^{\circ} \mathrm{C}$ for $1 \mathrm{~h}$

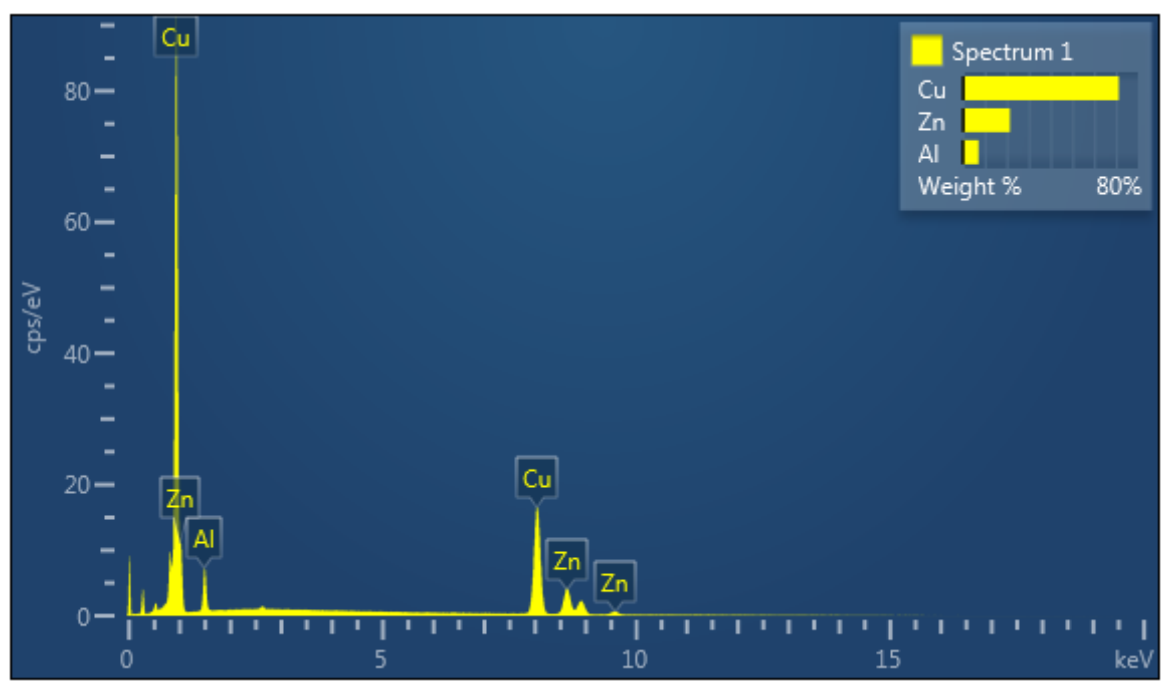

Figure 11 EDS analysis of the investigated alloy quenched from $900^{\circ} \mathrm{C}$ and aged at $400^{\circ} \mathrm{C}$ for $1 \mathrm{~h}$ 
The X-ray diffraction data collected for the quenched sample of alloy, showed in Figure 12, indicates a predominantly mar tensitic structure, with the relevant peaks in the $40^{\circ}$ to $45^{\circ} 2 \theta$ range.

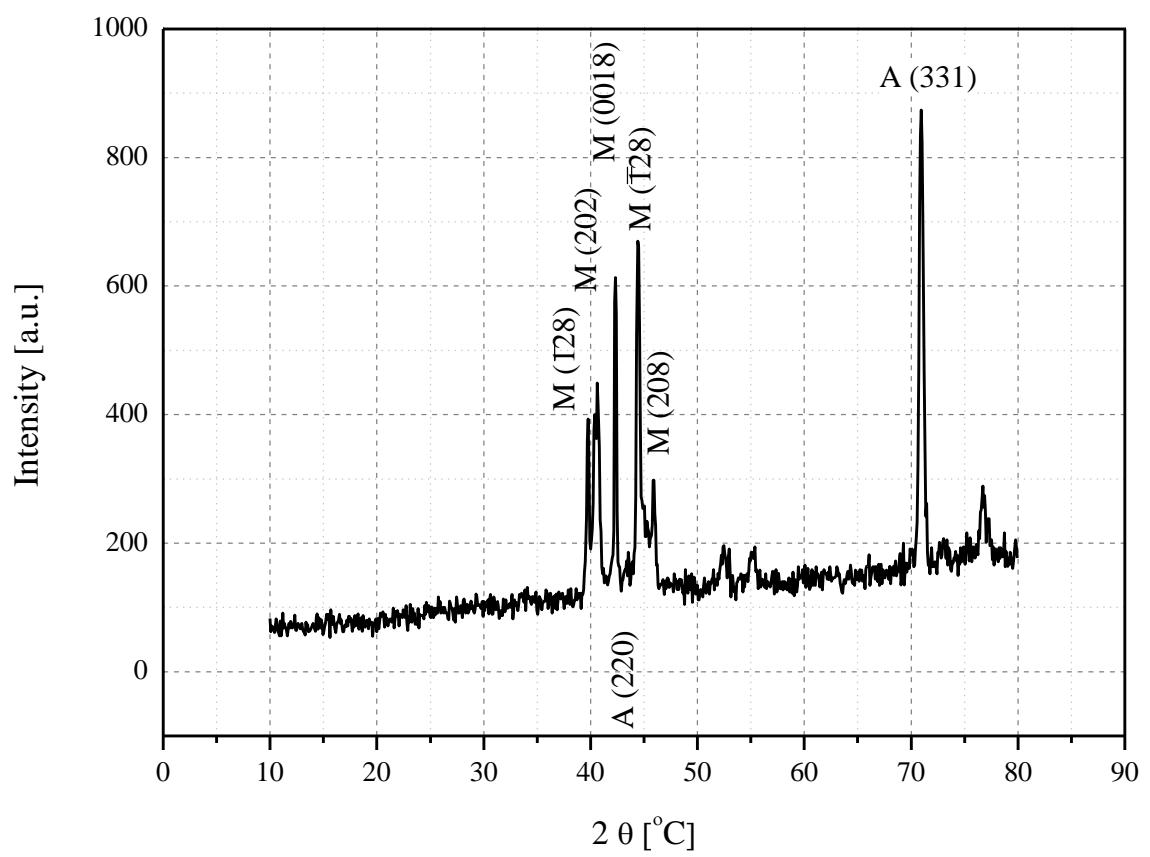

Figure $12 X$-ray diffractogram of the quenched alloy

\section{CONCLUSIONS}

The copper-based shape memory alloys with zinc and aluminum was manufactured, plastically deformed, heat treated and characterized in terms of the physic mechanical, structural and micro - structural analysis.

Quenching in water, following heating at $850^{\circ} \mathrm{C}$ and $900^{\circ} \mathrm{C}$, lead to the observation of a typical martensitic microstructure, with the twins revealed by the optical and electron microscopy.

The presence of martensite in the structure was further confirmed through an X-ray diffraction.

Severe plastic deformation lead to an increase of hardness compared to the unde- formed samples, a more pronounced increase was observed for the quenched samples.

Establishing a correlation between the material state, microstructure and mechanical properties, it can be concluded that the combination of thermo-mechanical processing regime, can achieve such a state of the material that provides the good mechanical properties.

Reducing the particle size $\alpha$-solid solution of hot processing increases the hardness and impact toughness compared to the ascast state.

Heat treatment of hot-processed alloy increases the hardness, while the impact 
toughness gradually decreases as the microstructure can be explained by the appearance of brittle phases, as a result of thermal deposition.

The optimal properties are obtained for material condition, subjected to the heat treatment, according to the following scheme: annealing at $850^{\circ} \mathrm{C}$ and $900^{\circ} \mathrm{C}$ $(10 \mathrm{~min})+$ quenched in water + aging at $400^{\circ} \mathrm{C}(1$ hour $)+$ air cooling.

\section{REFERENCES}

[1] Schetky, M.L.: Shape Memory Alloys, Sci. American, 11 (1979) 68-76.

[2] Otsuka, K., Shimizu, K., Suzuki, Y., Sekiguchi, Y., Taki, C., Homma, T., Miyazaki, S.: Splavi s Effektom Pamjati Form, Metallurgija, Moskva, 1990, p. 123. (in Russian)
[3] Wayman, C.M.: Shape Memory Alloys, Journal of Materials, 6 (1980) 129-137.

[4] Guilemany, J.M., Gil, F.J.: Kinetic Grain Growth in $\mathrm{Cu}-\mathrm{Zn}-\mathrm{Al}$ Shape Memory Alloys, Journal of Materials Science, 26 (1991) 4626-4628.

[5] Kostov A., Zivkovic Z.: ThermoDilatometry Investigation of the Martensitic Transformation in Copper-Based Shape Memory Alloys, Thermochimica Acta, 291 (1997) 51-57.

[6] Liang H., Chang Y.A.: A Thermodynamic Description for the Al-Cu-Zn System, Journal of Phase Equilibria, Vol.19, No.1 (1998) 25-37.

[7] Arsenovic, M., Kostov A.: Continuous Casting of Small-Cross Section Profiles, Naucna knjiga, Beograd, 2001, (in Serbian). 